\title{
Time on housework and selection into and out of relationships in Australia: a multiprocess, multilevel approach
}

Michele Haynes

m.haynes@uq.edu.au

Janeen Baxter

Belinda Hewitt

Mark Western

(Received May 2014
Institute for Social Science Research, The University of Queensland

Institute for Social Science Research, The University of Queensland

School of Social Science, The University of Queensland

Institute for Social Science Research, The University of Queensland

http://dx.doi.org/10.14301/Ilcs.v6i3.303

\section{Abstract}

In this paper we investigate the impact of relationship transitions on domestic labour time using longitudinal data from eight waves of the Household, Income and Labour Dynamics in Australia (HILDA) survey. Although there is a growing body of literature on this topic, previous research has failed to adequately address selection issues relating to transitions in marital status and time on housework. A simultaneous-equations model is used to jointly examine the relationships between time on housework and marital status transitions to allow for correlation between unobserved partner and person characteristics that impact on each process. Our results show that women who transitioned from being single into marriage spend more time on housework than women who transitioned from single to cohabiting. Additionally, we find that women who spend more time on housework when single also spend more time on housework after cohabitation or marriage. But there is no evidence of selection of these women into marriage rather than cohabitation. We also found no evidence to support the hypothesis that women who do varying amounts of housework are more likely to select out of relationships. Overall we conclude that the unobserved factors influencing time spent on housework are not related to the unobserved factors influencing relationship transitions.

Keywords: multiprocess models; multilevel models; domestic labour; marital transitions; self-selection

\section{Introduction}

Previous research has shown that life course events, such as transitions into and out of relationships, are associated with large variations in women's time on domestic labour (Gupta, 1999; Baxter, Hewitt \& Haynes 2008). What has not been examined, however, is whether these processes are interrelated, with factors that lead to variations in housework hours also influencing the likelihood of making certain relationship transitions. Research has shown that women who cohabit spend less time on domestic labour than women who are married (Shelton \& John, 1993; South \& Spitze, 1994; Baxter, 2005). Similarly, we know that women who separate from a union experience a decline in the amount of time spent on housework (Gupta 1999; Baxter, Hewitt \& Haynes, 2008). What is unclear from previous research is whether these variations in housework time are due to relationship transitions, or other unobserved characteristics that are driving both relationship transitions and time spent on housework. 
Less time on housework by cohabiting women may be due to the experience of cohabitation or the values, attitudes or preferences that influence both the amount of time women spend on housework and their decisions about union type. Similarly women who separate from a union may find that there is less housework to be done after separation. Alternatively the characteristics that lead women to spend less time on housework when partnered may also increase the likelihood of separation.

Disentangling cause from selection drives much social science research, for example the male marriage wage premium (Ginther \& Zavodny, 2001; Dougherty, 2006), the relationship between health and unemployment (Lundin, Lundberg, Hallsten, Otosson \& Hemmingsson, 2010) and the intergenerational reproduction of socioeconomic status and inequality (McLanahan \& Perchesky, 2008). On the present topic, we know that women's time on housework is linked to union formation and dissolution, but we do not understand the underlying processes. The reasons for differences in housework time for women in different relationship states have been postulated rather than explicitly investigated.

The aims of this paper are twofold. First, we identify the joint influence of observed and unobserved factors on relationship transitions and housework time. Second, we examine if there is a selection effect from single into a marital or cohabiting union for women who spend more time on domestic work, or a selection effect from cohabiting or married to single for women who spend less time on housework. We use eight waves of panel data from the Household, Income, and Labour Dynamics in Australia (HILDA) survey to investigate the interrelationships between women's time on housework and relationship transitions.

We go beyond the single process model typical of most social science research to jointly model the processes of union formation and dissolution and housework hours using multiprocess, multilevel models (for examples of the application of these models to other life events see Steele, Kallis, Goldstein \& Joshi, 2005; Steele, 2011). In these models observed factors are incorporated as independent variables in the equation for each process simultaneously, while unobserved person characteristics that impact on each process are permitted to co-vary. This emerging approach enables us to examine the extent to which relationship transitions and housework hours are linked and jointly determined by both observed and unobserved factors.

\section{Time on Housework and Relationship Transitions}

Women in cohabiting or marital partnerships spend more time on domestic labour than unpartnered women (Gupta, 1999; Baxter, Hewitt \& Haynes, 2008; Baxter, Haynes \& Hewitt, 2010). One possible explanation for this difference, according to a gender display approach, is that women in partnerships create and affirm their gender identity as partnered women by spending more time on certain female-defined housework tasks compared to single women. Female-defined housework tasks require considerable investments of time and energy on a regular basis, such as cooking, cleaning and laundry, compared to male-defined housework tasks such as lawn mowing or home repairs, which may be seasonal or irregular. Researchers have argued that married women are more likely to display gender by spending time on housework than women in other relationship states (Berk, 1985; Bittman, England, Sayer, Folbre and Matheson, 2003). The gender display approach has been recently subject to critique and re-evaluation (Sullivan, 2011), but nevertheless has been an extremely influential approach for housework research in many countries, including the United States, Europe and Australia, explaining why gender divisions of labour in households have proved so intractable (Treas \& Drobnič 2010).

Other well-known explanations for women's time on housework have focused on household specialisation or bargaining often using measures of relative earnings to assess how couples make decisions about who should spend most time on unpaid housework tasks and who should specialise in paid work (Brines, 1994). Since women typically earn less than men they also typically devote a greater proportion of their time to unpaid work than men, either because they have less bargaining power or because of the perceived household utility of gender specialisation. Gupta's recent work $(2006,2007)$ has 
taken debates about earnings and housework time in a new direction by arguing that women's time on housework is related to their absolute rather than their relative earnings. This has led to a rethinking of the links between earnings and housework time. One possibility is that women use their earnings to purchase household help, thereby reducing their time on housework. Alternatively, higher earning women may have different orientations toward housework than women with lower earnings, with higher earning women less interested in doing housework, or with different preferences and beliefs about appropriate standards of tidiness and cleanliness. While Gupta's research has been supported by studies in the United States and some parts of Europe (Gupta, Evertsson, Grunow, Nermo \& Sayer, 2010), recent work in an Australian context has found stronger support for relative rather than absolute earnings suggesting that institutional context may play a part in household bargaining over money and time (Baxter \& Hewitt 2013).

Most previous research, with the exception of Gupta (2007) and Gupta and Ash (2009) has focused on understanding why women spend more time on housework than men rather than why partnered women spend more time on housework than single or separated women. Focusing specifically on within gender variation, shifts the focus to explaining how life course events may be related to housework patterns, and in turn lead to gender differences. It also enables consideration of how women respond to changing social contexts, in this case changes in their relationship status. As several studies have shown, time on housework is not static across the life course (Gupta 1999; Gershuny, Bittman \& Brice 2005; Baxter, Hewitt \& Haynes 2008). Women's and men's time on housework varies in relation to changing employment status, parenthood and marital status. In some cases, the change in housework time may be immediate, while in others it may undergo a process of "lagged adaptation" whereby men and women gradually change their behaviour in response to changing social context (Gershuny, Bittman \& Brice 2005). In most cases, the evidence is clear that women's housework time changes much more than men's.

In the case of relationship transitions, changes in housework may be influenced by changes in beliefs, habits and norms about appropriate behaviours in relationships, but also changes in the household context. The transition to a partnership may be associated with other important changes in a woman's life course that occur at the same time and are related to time spent on housework. For example, the decision to cohabit or marry may be closely linked to decisions about having a child, buying a house or reducing time spent in employment. Research has shown that fertility decisions are linked to transitions between cohabitation and marriage (Steele, Kallis, Goldstein \& Joshi, 2005) and the birth of a child, particularly a first child, leads to large increases in women's time on housework (Baxter, Hewitt \& Haynes, 2008). These co-occurring events, perhaps reciprocally related to decisions about partnership transitions, may also lead to women spending longer amounts of time on housework.

At the same time, the characteristics that select some women into cohabiting rather than marital relationships may also influence how much time they spend on housework. Considerable research has examined the observable characteristics that lead to women's likelihood of marriage, such as education, earnings, employment characteristics and ethnicity (Oppenheimer, 1997). But there may also be unmeasured or unobservable characteristics relating to aspirations and decisions about having a child, buying a house or reducing time spent in employment that influence women's time on housework and the decision to cohabit or marry. For example, women who wish to have a large family may also prefer the more traditional and permanent union of marriage, and have plans to buy a large house to accommodate the family for a long period of time with aspirations to keep a clean and aesthetically pleasing home. On the other hand, women who intend to develop their career and do not wish to have children in the immediate future may choose to cohabit, preferring a union without long-term commitment and less focus on the home. These same fertility intentions, employment and housing decisions may also influence the time that women spend on housework with those wanting a large family, a long-term marital relationship and a larger house, more likely to spend larger amounts of time on housework both before and after union and family formation. 
Additionally, the amount of housework that a woman performs when unmarried may be influenced by domestic standards, habits or orientations. These same unmeasured standards may mean that these women will be more likely to marry than those who do not have these same domestic standards or orientations. Similarly, women who are less domestically inclined may be more likely to separate from a partnership than their counterparts. In other words, the formation and dissolution of marital partnerships, and decisions about whether to cohabit or marry, may be influenced by measured covariates such as age, education, earnings and attitudes, as well as unobserved factors such as a woman's propensity to spend time on housework, or what might be termed her level of domestic proclivity'.

In other words, unmeasured characteristics, such as housework proclivity, may be related to women's decisions about types of partnership formation. Women with less interest in domesticity and weaker housework proclivity may be more likely to form a cohabiting relationship than a marital relationship. Alternately, women with higher levels of housework proclivity may be more likely to remain in a marriage than those with weaker housework proclivity. If marriage is viewed as a more traditional and conventional form of partnering than cohabitation, it may be more attractive as a form of partnership for those with more traditional views about gender roles and those who have higher levels of domestic proclivity. These same orientations may also discourage women from leaving a marital relationship. Where such unmeasured variables jointly determine relationships and housework time, assumptions about the exogeneity of explanatory variables in standard single process models are violated and the estimation of causal effects is compromised (Cameron \& Trivedi, 2005). For example, although fixed effects panel regression models automatically control for all time invariant unobservable characteristics, they do not provide an assessment of selection bias or the interrelationships among dynamic processes.

In previous research, domestic orientations are often assumed to be captured by responses to questions about gender role attitudes. However, these questions are typically framed in terms of whether men or women should do domestic work and the importance of task sharing between partners. In other words, such questions focus more on issues of gender equality within the household than orientations toward domestic work. Moreover, despite the assumption in much of the housework literature that all household tasks are unpleasant and to be avoided at all costs (Ahlander \& Barr 1995), some women may experience housework as enjoyable and rewarding. While this is perhaps less plausible for certain activities, it is possible that activities such as cooking may be regarded as relaxing and pleasant and not too dissimilar to leisure activities. They may provide an outlet for aspects of creativity and imagination that are not possible in other areas, such as employment. If women enjoy doing specific kinds of household work it is likely that they will spend more time on it than women who do not, regardless of their relationship status. It is therefore important to capture unmeasured characteristics in models explaining time on household work.

In the current paper our concern is whether women with certain unmeasured characteristics are more likely to select into, or out of, relationships than others and to spend greater or lesser amounts of time on housework. We only examine women's transitions because life course events have a much greater effect on women's housework hours than men's (Baxter, Hewitt \& Haynes, 2008), and focusing on within gender variations enables a stricter, within-person, examination of the relationship between life course events and time on housework than the usual approach of comparing the determinants of women and men's housework time. Women's housework hours vary considerably in relation to marital, parental and employment status with women generally increasing their hours in response to the formation of partnerships and the arrival of children, typically in combination with a reduction in paid work hours outside the home. Men's housework hours, on the other hand, tend to remain relatively stable regardless of marital, parental or employment status.

Previous research has only considered the effects of marital status transitions on housework time without considering the reciprocal influence of housework time on the type of marital status chosen. 
This one-sided approach fails to acknowledge that women's aspirations for a family and a long-term relationship may be interrelated with their proclivity to do housework. Although we may expect that women's time on housework increases by differing amounts with the transition into a cohabiting relationship or marriage, it is also possible that women who are predisposed to doing more housework are more likely to marry than to cohabit outside marriage. However, if women who do more housework typically select into marriage rather than a cohabiting relationship, this could lead to biased estimates of the effects of marital transitions on housework time. We consider time spent on housework and transitions between different types of relationship status as multiple related dynamic processes. In this approach, the same unmeasured individual characteristics are assumed to affect each process. The unobserved variables are represented by individual-specific random effects in all models for housework time and marital transitions and these random effects are allowed to co-vary to adjust for selection bias in model parameter estimates.

Relationship transitions and fertility (Steele, et al. 2005, Steele, Kallis \& Joshi, 2006; Upchurch, Lillard \& Panis, 2002), and housing transitions and fertility (Kulu \& Steele, 2013) have previously been analysed as related multistate processes by using a system of simultaneous equations with co-varying random effects. We take a similar approach in this paper by considering time spent on housework and relationship transitions as interrelated multistate processes and analyse eight waves of data from the HILDA survey. We address three key questions:

1. What is the effect of relationship transitions on women's time on housework?

2. Is there a selection effect of women who spend more time on domestic labour into partnerships compared to women who spend less time on domestic labour, and specifically into marriage rather than cohabitation?

3. Is there a selection effect of women who do less domestic labour out of partnerships, and specifically out of marriage compared to cohabitation?

\section{Methods}

\section{Data and sample}

Our data come from the first eight waves of the Household, Income and Labour Dynamics in Australia (HILDA) survey collected between 2001 and 2008. Wave one comprised 7,682 households and 13,969 individuals (Watson \& Wooden, 2002a and 2002b). Households were selected using a multi-stage sampling approach, and a $66 \%$ response rate was achieved (Watson \& Wooden 2002a). Within households, data were collected from each person aged over 15 years (where available) using face-toface interviews and self-completed questionnaires, and a $92 \%$ response rate was achieved (Watson \& Wooden 2002a). Waves two to eight had, respectively, response rates of $86.8 \%, 90.4 \%, 91.6 \%$, 94.4\%, 94.9\%, 94.7\% and 95.2\% (Watson and Wooden, 2012).

Our analytic sample included all women of childbearing age from 18-45 years. We excluded women who were widowed before and during the survey and those with missing values for housework hours, marital status and other variables measuring life course transitions, such as fertility. It was not possible to determine if a relationship transition had occurred for some relationship statuses immediately prior to wave one and therefore the final HILDA sample retained for analysis was taken from waves two to eight and comprised 3,392 women with a total of 18,376 person years and an average of 5.4 wave observations per person.

\section{Measures \\ Dependent variable}

HILDA collects a range of time use measures. The main outcome measure in this study is hours spent doing housework each week. Respondents were asked questions about the hours they spend in a typical week on housework (preparing meals, washing dishes, cleaning house, washing clothes). Similar measures have been used in many other housework studies (Gupta, 1999). The distribution of this variable was skewed, and was therefore logged for inclusion in the models. 
Some research has relied on measures of the proportion of housework done by the respondent, or the housework share within couples operationalised as the percentage distribution or the ratio of women's housework hours to men's housework hours (Coltrane, 2000). These measures are particularly suited to research examining issues of gender equality within couples. Since our focus is on women across various relationships states, including single, and we are concerned with explaining how unmeasured characteristics, such as domestic proclivity, is associated with relationship transitions, housework hours is more appropriate in the current analyses.

\section{Relationship transitions}

Respondents were asked their current marital status at each wave, including married, cohabiting (living together but not legally married), separated, divorced, widowed and never married. We collapse marital status at each wave to three relationship states: Married, cohabiting, and single (including never married, separated and divorced) and identify eight transitions of interest between these relationship states: married - married; married single; cohabiting - cohabiting; cohabiting - single; cohabiting - married; single - single; single - married; and single - cohabiting.

\section{Control variables}

We include two measures for children. The first is a categorical measure for the number of dependent children (defined as 18 and under) including $1=$ no children, $2=1$ child, $3=2$ children, and $4=3$ or more children. The second measure indicates whether the respondent had a birth between waves with $1=$ no birth, and 2 = birth. We also include a range of controls that have been found to be associated with housework and relationship transitions. These include age of respondent in years and age squared, earnings, education ( 1 = attained bachelor degree or higher, 2 = other), employment status ( $1=$ not employed, $2=$ employed full time, 3 = employed part time) and duration in marital status (months married, cohabiting or single). We include a measure for gender role attitude in response to the statement: 'It is much better for everyone involved if the man earns the money and the woman takes care of the home and children'. Responses ranged from 1 = Strongly
Disagree to $7=$ Strongly Agree. This question was asked in wave one and wave five. In our models, we carried wave one values on this variable forward for waves two to four and carried wave five values forward for waves six to eight. All measures are time varying with descriptive statistics for each shown in table 1 . We do not discuss the associations between these control variables and housework time from our multivariate models presented below, as our findings are similar to those reported in many other studies and these associations are not the focus of the current paper.

\section{Analytic approach}

To jointly examine the relationships between time on domestic labour and marital status transitions we use a simultaneous equations approach with correlated error variances between equations reflecting common unobserved variables. Using this approach the formation and dissolution of relationships is analysed as a multistate process that may be influenced by measured covariates and unobserved factors that measure a woman's propensity to spend time on housework, such as her degree of domesticity. For each woman in the sample data, we observe measures for housework hours and marital status on up to eight occasions and we also observe when a marital transition representing a relationship formation or dissolution occurs. In the models for marital status transitions, we include a term for lagged housework hours to investigate whether the observed measure of time spent on housework immediately prior to a transition is associated with the type of relationship transition. Because we have repeated observations on each woman, and a transition can occur more than once for a woman, then housework hours and transitions are considered to be nested within individuals and an approach using a multilevel model specification which maintains the time-ordering of the observed transitions is appropriate. In our sample data from HILDA, 1,349 relationship transitions are observed.

In an approach similar to that taken by Steele, et al. $(2005,2006)$ among others, we use a multiprocess multilevel model where a system of regression equations with random coefficients is estimated simultaneously. The data analysed by Steele et al. $(2005,2006)$ contain complete event histories for the 
formation and dissolution of adult de facto and marital partnerships as well as for other outcomes of interest such as the birth of a child which allows the specification of a multilevel multistate event history model to analyse duration until an event occurs. The HILDA survey does not collect a complete event history for de facto relationships and it is not easy to collect reliable retrospective data on housework hours. However we can compute the duration of the marital status at wave one and the duration of subsequent marital status events. With eight waves of data we therefore analyse the likelihood of a marital transition from wave one using multinomial models and including marital status duration as an independent variable in the model.

Our multiprocess model includes a linear mixed model for logged housework hours and different multinomial logit models with random intercepts for transitions into and out of partnerships (Pettitt, Tran, Haynes \& Hay, 2006). The model component for logged housework hours (model 1) includes an indicator variable for each marital status and the indicator variables are interacted with each covariate in the model. Random coefficients are specified for the indicator variables. Three additional models are specified separately for transitions into a partnership (model 2: from single state to cohabiting or married), for transitions out of a cohabiting partnership (model 3: from cohabiting to married or single) and for transitions from marriage to single (model 4). We analyse the likelihood of a transition occurring at any point in time and hence models 2 and 3 are multinomial logit models with random intercepts and model 4 is a binary logit model with a random intercept. For models 2 to 4 the reference outcome is no transition. The random effects from models 1 to 4 are correlated and are drawn from a multivariate normal distribution with mean vector zero and variance-covariance matrix $\boldsymbol{\Sigma}$. The model specification and estimation procedure is described below.

\section{Model 1: A linear mixed model for housework hours with random coefficients on indicator variables for single, cohabiting and married statuses.}

$$
\begin{aligned}
& \ln \left(\mathrm{y}_{\mathrm{ti}}\right)=b_{0}^{\mathrm{k}}+\mathrm{b}_{1}^{\mathrm{k}} \text { Age }_{\mathrm{ti}}+\mathrm{b}_{2}^{\mathrm{k}} \text { Age }_{\mathrm{ti}}^{2}+\mathrm{b}_{3}^{\mathrm{k}} \text { Earnings }_{\mathrm{ti}}+\mathrm{b}_{4}^{\mathrm{k}} \text { Attitude }_{\mathrm{ti}}+\mathrm{b}_{5}^{\mathrm{k}} \text { Birth }_{\mathrm{ti}}+\mathrm{b}_{6}^{\mathrm{k}} \text { One_child }_{\mathrm{ti}}+ \\
& \mathrm{b}_{7}^{\mathrm{k}} \text { Two_children }_{\mathrm{ti}}+\mathrm{b}_{8}^{\mathrm{k}} \text { More_children }_{\mathrm{ti}}+\mathrm{b}_{9}^{\mathrm{k}} \mathrm{FTemp}_{\mathrm{ti}}+\mathrm{b}_{10}^{\mathrm{k}} \text { PTemp }_{\mathrm{ti}}+\mathrm{b}_{11}^{\mathrm{k}} \text { Duration }_{\mathrm{ti}}+ \\
& \mathrm{b}_{12}^{\mathrm{k}} \text { Trans }_{\mathrm{ti}}+\mathrm{b}_{13}^{\mathrm{k}} \text { Trans }_{\mathrm{ti}}+\alpha_{1 \mathrm{ki}}
\end{aligned}
$$

The variable $Y$ with response $y_{t i}$ is used to denote housework hours for woman $i$ at wave number $t=$ $2, \ldots, 8$. All covariates are interacted with the relationship state indicator variables $I_{k}$. The fixed regression constants and coefficients are denoted $b_{l}^{k}$ where the superscript $k$ denotes relationship status: $s$ = single, $\mathrm{c}=$ cohabiting, $\mathrm{m}=$ married and $I=0,1, \ldots, 13$ is a variable specific number corresponding to each of the explanatory variables in the model. The superscript $k$ for each of the variable coefficients indicates that the variable has been interacted with the indicator variable $I_{k}$ for the corresponding relationship status producing an estimated regression coefficient for each relationship status. For the single status ( $k=1)$ the variable Trans1 represents the transition to cohabiting, and Trans2 represents the transition to marriage. For the cohabiting status $(k=2)$ the variable Trans1 represents the transition to single and Trans 2 represents the transition to marriage. For the married status $(k=3)$ the variable Trans1 represents the transition to single and the coefficient $b_{13}^{3}=0$. The term $\alpha_{1 k i}$ represents the individualspecific random intercept term associated with relationship status $k$ in model 1 with mean zero and variance component $\sigma_{1 k}^{2}$. 


\section{Model 2: A multinomial logit model for transitions out of the single state with no transition as the reference category and a random intercept for each transition.}

$$
\begin{aligned}
& \ln \left(\frac{\operatorname{Pr}\left(Z_{1 \mathrm{ti}}=p\right)}{\operatorname{Pr}\left(Z_{1 \mathrm{ti}}=0\right)}\right)= \\
& \mathrm{g}_{0}^{\mathrm{p}}+\mathrm{g}_{1}^{\mathrm{p}} \text { Age }_{\mathrm{pti}}+\mathrm{g}_{2}^{\mathrm{p}} \text { Age }_{\mathrm{pti}}^{2}+\mathrm{g}_{3}^{\mathrm{p}} \text { Lag_earnings }_{\mathrm{pti}}+\mathrm{g}_{4}^{\mathrm{p}} \text { Degree }_{\mathrm{pti}}+\mathrm{g}_{5}^{\mathrm{p}} \text { One_child }_{\mathrm{pti}}+ \\
& \mathrm{g}_{6}^{\mathrm{p}} \mathrm{Two}_{\text {c children }}{ }_{\mathrm{pti}}+\mathrm{g}_{7}^{\mathrm{p}} \text { More_children }_{\mathrm{pti}}+\mathrm{g}_{8}^{\mathrm{p}} \text { Birth }_{\mathrm{pti}}+\mathrm{g}_{9}^{\mathrm{p}} \text { Duration }_{\mathrm{pti}}+ \\
& \mathrm{g}_{10}^{\mathrm{p}} \text { Lag_HWHours }_{\mathrm{pti}}+\alpha_{2 \mathrm{pi}}
\end{aligned}
$$

The variable $Z_{1}$ denotes the relationship status $p=$ $0,1,2$ into which a transition is being made, where 0 = no transition, 1 = cohabiting, 2 = married. The fixed regression constants and coefficients are denoted $g_{j}^{p}$ where $p=1,2$ and $l=0,1, \ldots, 10$ is a variable specific number corresponding to each of the explanatory variables in the model. The term $\alpha_{2 p i}$ represents the individual-specifc random intercept term associated with model 2 and the transition to relationship status $p$ with mean zero and variance component $\sigma_{2 p}^{2}$ Models 3 and 4 are specified similarly to model 2 . Model 3 is a multinomial logit model for transitions out of cohabitation and model 4 is a binary logit model for transition out of marriage to separation with no transition as the reference category.

\section{Model Estimation}

For the multinomial logit models we allow the random effects across the two transition states for each of these models to co-vary. Non-zero correlations among random effects across the models may occur if the unobserved characteristics that influence a woman to do more housework in any of the relationship states also influence the decision to form or dissolve a partnership. Also, if a woman experiences several transitions across the eight waves it is possible that the propensity to undergo one type of transition may also influence the likelihood of her undergoing another transition. Therefore, all eight random effects from models 1 to 4 are specified to arise from a multivariate normal distribution with mean vector zero and variance-covariance matrix $\boldsymbol{\Sigma}$. That is, using the notation above for models 1 to 4 , we define the simultaneous nature of the estimation process through the matrix of correlated random effects specified as

$$
\alpha=\left(\alpha_{11}, \alpha_{12}, \alpha_{13}, \alpha_{21}, \alpha_{22}, \alpha_{31}, \alpha_{32}, \alpha_{41}\right) \sim N(0, \Sigma) \text {. }
$$

The system of equations specified in models 1 to 4 form the multiprocess multilevel model. The parameters in each of the equations are estimated simultaneously using Markov chain Monte Carlo (MCMC) simulation (Gelman, et al., 2005) which is implemented using the freely available WinBUGS software (Spiegelhalter, et al., 1998). Non-informative normal prior distributions were specified for each of the regression parameters. A Wishart prior distribution (dimension eight) was specified for inverse $\boldsymbol{\Sigma}$. Similar methods have been used to estimate multinomial logit models with random effects for estimating the probability of employment for immigrants to Australia with time since arrival (Pettitt, et al., 2006) and the probability of employment for Australian women (Haynes, Western, Yu \& Spallek, 2008).

\section{Results}

The results from the estimation of the multiprocess model defined by models 1 to 4 are shown in tables 2 to 5 . All results are means of posterior distributions obtained from 46,000 MCMC simulations following a burn-in length of 4,000 simulations. Table 2 shows the estimated regression coefficients for logged housework hours from model 1. Table 3 shows the estimated regression effects for the log odds of partnership formation and table 4 shows the estimated regression effects for the log odds of partnership dissolution. Table 5 is a summary table that shows the estimated variance-covariance matrix for the eight random effects from models 1 to 
4. We discuss the results for each of our research questions in turn.

\section{What is the effect of a relationship status transition on women's time on housework?}

Model 1 addresses this question in two ways. First, the positive correlations $(\rho>0.60)$ among the random effects for time spent on housework in each relationship status (shown in the top left 3 rows and columns of table 5) suggest that women with a propensity to high (low) levels of housework or domesticity when single also have a propensity to spend more (less) time on housework relative to other women, when in a partnership. Second, the regression coefficients for estimating the effect of a relationship transition on housework time (table 2) show that the formation of a relationship is associated with a significant increase in housework hours and that the effect of a transition into marriage $(b=0.333, S E=0.064)$ is twice as high as the effect of a transition into cohabitation $(b=0.169, \quad S E=0.033)$. Thus, women who enter a marital union spend more hours on housework than women who enter a cohabiting union. Table 2 also shows that separation from a cohabiting relationship is associated with a significant reduction in housework hours $(b=-0.104$, $\mathrm{SE}=0.047)$.

Together, these findings suggest that women's housework hours increase with a transition into a relationship, and also if a woman spends more than average time on housework hours when she is single then she will also tend to spend more than average time on housework when she is in a cohabiting or marital relationship. This result suggests that some marital transitions do influence the change in time spent on housework but that the total amount of housework undertaken following a transition is to an extent influenced by the propensity of a woman to spend more or less than average time on housework before the transition takes place.

\section{Is there a selection effect of women who spend more time on domestic labour into marital rather than cohabiting partnerships?}

A selection effect of this type can be assessed by examining the effects of observed housework time on relationship transitions as well as the correlations among unobserved variables, measured by the random effects in model 1 and the random effects in models 2 to 4 . If the random effects for time spent on housework are positively correlated with the random effects for a relationship transition then this result signals the presence of a selection effect on the relationship status, with regards to housework time. Tables 3 and 4 show that there is no significant association between housework time prior to a relationship transition and the type of relationship transition experienced. Further, table 5 shows that the correlations between the random effects from model 1 and the random effects from models 2-4 are not significantly different from zero. Hence, there is no supporting evidence that women who spend more time on domestic labour are more likely to select into marriage rather than cohabitation, from either the observable or unobservable variables related to housework time.

\section{Is there a selection effect of women who do less domestic labour out of partnerships?}

The correlations of random effects presented in table 5 show that there are no significant associations among the random effects for time spent on housework and transitions out of partnerships. Therefore there is no evidence of a selection effect of this type in our sample. Thus women who spend less time on housework in a relationship are not more likely to separate than women who spend more time on housework.

However, significant correlations occur among the random effects for the transition from single into cohabitation and the transition from cohabitation to marriage, the transition from cohabitation to separation and the transition from marriage to separation. While it is not surprising that women who form a cohabiting relationship will either separate or go on to marry, it is noteworthy that the unobserved characteristics of women who cohabit are positively correlated with the unobserved characteristics of women who separate from marriage $(\rho=0.612)$. This suggests that women with unobserved characteristics that are more likely to encourage them to enter a cohabiting relationship before marriage, are also more likely to encourage them to separate from marriage compared to those who marry directly. This supports previous research that has found a link 
between premarital cohabitation and marital separation (Dush, Cohan \& Amato, 2003).

\section{Discussion}

Many life course events are interrelated. Indeed one hallmark of a life course approach is the recognition that trajectories and transitions in different life domains are interconnected rather than distinct (Han \& Moen, 1999). Despite this, most previous research, including longitudinal research on the effects of marital transitions on housework time, treats this association as a single-state process that is independent of events occurring in other life domains. This can lead to selection and unobserved heterogeneity biases that call into question research findings.

We have investigated whether observed and unobserved characteristics that influence women's decisions about whether to cohabit, marry or separate, also influence their time spent on housework. This approach allows us to more accurately assess the mechanisms underpinning change in women's housework time when they transition into and out of relationships. To our knowledge this is the first paper to use multilevel, multiprocess models to examine these associations.

Overall our results suggest that movement into a relationship increases women's time on domestic labour. We find that women who transition from being single into marriage spend about twice as much time on housework as women who transition from single to cohabiting. There was no significant change in housework hours for women who transitioned from cohabiting to married. This is consistent with previous research that finds that married women do more housework than cohabiting and single women (Baxter, 2005; Shelton \& John, 1993; South \& Spitze, 1994). A key explanation given for this gap in housework hours between women who are cohabiting compared to those who are married is that the types of women who choose different relationship arrangements differ in their values, norms and domestic orientations (Baxter, Haynes, \& Hewitt, 2010). Thus women with different preferences select into either marriage or cohabitation.
In this paper we have directly investigated this assumption examining whether the increase in housework hours is due to the characteristics of the kinds of women who partner or the result of circumstances arising after partnership. This enables us to address questions of selection and effect that have not been adequately addressed in previous studies. Moreover we were able to investigate whether unobserved characteristics relating to women's time on housework determine what kind of partnership, cohabiting or married, they enter, and whether these unobserved characteristics are related to women's decisions to leave a partnership.

Our results show that women who spend more time on housework when single, also spend more time on housework after cohabitation or marriage. But there is no evidence of selection of these women into partnerships. Women who do more housework when single are not more likely to form a partnership, and neither are they more likely to choose to marry than cohabit, compared to women who do less housework when single. We also found no evidence to support the hypothesis that women who do varying amounts of housework are more likely to separate from cohabitation or marriage. This suggests that some women are more likely to do housework irrespective of the type of relationship they are in, or transitions into and out of relationships.

Overall we conclude that the unobserved factors influencing time spent on housework are not related to the unobserved factors influencing relationship transitions. This is an important finding because it suggests that the increase in housework time experienced by women when they partner is the result of the transition into a partnership, rather than reflecting characteristics of women who partner. Eliminating selection into partnership as an explanation allows researchers to focus on the transition to partnership itself as the cause of increased housework time, which potentially yields new research questions and possibilities. Indeed if we think of the transition into a partnership as being analogous to a social mobility trajectory from an origin state to a destination state, over 45 years ago, Duncan (1966) argued that in analysing the effects of such movements, one needed to distinguish the main effects of origin and destination on an outcome from 
the effect of mobility per se. Duncan's work stimulated the mobility effects literature into attitudes and behaviours (Sobel, 1981) which continue today (e.g., Tolsma, de Graaf \& Quillian, 2009). In this context, our research suggests a number of potential hypotheses that could be examined in the future. If the mobility process is important, rather than the destination state (partnership) for instance, different trajectories into partnership should lead to different outcomes on housework. On the other hand, if it is partnership per se that is important, the trajectory should be unimportant as long as the destination state is the same. Similarly, if there is a mobility effect on housework time, and the mobility mechanism can be directly measured (for example normative understandings of housework and gender roles that reflect origin and destination characteristics), the change in housework hours associated with a transition should not be equal to the additive effects of the mechanism in origin and destination.

In contrast to our findings for the effects of selection/unobserved heterogeneity on relationships and housework, we do find that the unobserved characteristics influencing women to cohabit prior to marriage also influence their likelihood of separation from marriage. Previous research has shown that couples are more likely to separate if they have cohabited prior to marriage compared to those who have married directly (Dush, Cohan \& Amato, 2003). Our results support this finding by showing that women who select into cohabitation prior to marrying are also more likely to select out of marriage. Again, the implication of this result is that some characteristics of women (e.g. values, attitudes, preferences) are associated with cohabitation and separation and these characteristics should be incorporated into future theorising and empirical research.

More broadly, we have also endeavoured to show how multiprocess multilevel models for jointly cooccurring social events can be useful for life course analyses, and social science more generally. A great deal of basic and applied empirical work in the social sciences is motivated by the need to address questions of cause and effect (Morgan and Winship, 2007) and some have even argued that science is defined by the ability to formally specify and examine proper causal statements in theory, hypothetical populations and with real data (Heckman, 2005). With non-experimental data, unobserved heterogeneity, selection and other related issues linked to sampling variability, compromise our ability to identify causal effects, even if we can properly specify causal statements in theory and for hypothetical populations. Multiprocess multilevel models provide yet another approach to addressing some of these issues.

\section{Acknowledgements}

This paper uses unit record data from the Household, Income and Labour Dynamics in Australia (HILDA) Survey. The HILDA Project was initiated and is funded by the Australian Government Department of Social Services (DSS) and is managed by the Melbourne Institute of Applied Economic and Social Research (Melbourne Institute). The findings and views reported in this paper, however, are those of the author and should not be attributed to either DSS or the Melbourne Institute.

\section{References}

Ahlander, Nancy Rollins \& Barr, Kathleen Slaugh. (1995). Beyond Drudgery, Power, and Equity: Toward an Expanded Discourse on the Moral Dimensions of Housework in Families. Journal of Marriage and the Family, 57 (1), 54-68. http://dx.doi.org/10.2307/353816

Baxter, J. (2005). To Marry or Not to Marry: Marital Status and the Household Division of Labor. Journal of Family Issues, 26 (3), 300-321. 
http://dx.doi.org/10.1177/0192513X04270473

Baxter, J., Haynes, M. \& Hewitt, B. (2010). Pathways into Marriage. Life course Patterns and the Domestic Division of Labor. Journal of Family Issues, 31, 1481-1506. http://dx.doi.org/10.1177/0192513X10365817

Baxter, J. \& Hewitt, B. (2013) Economic independence or bargaining power? The relationship between women's earnings and housework time. Feminist Economics, 19 (1), 29-53.

Baxter, J., Hewitt, B. \& Haynes, M. (2008). Life Course Transitions and Housework: Marriage, Parenthood and Time on Housework. Journal of Marriage and the Family, 70, 259-272. http://dx.doi.org/10.1111/j.1741-3737.2008.00479.x

Berk, S. Fenstermaker (1985). The Gender Factory. New York: Plenum. http://dx.doi.org/10.1007/978-1-4613-2393-8

Bittman, M., England, P., Sayer, L., Folbre, N. and Matheson, G. (2003). When Does Gender Trump Money? Bargaining and Time in Household Work. American Journal of Sociology, 109, 186-214. http://dx.doi.org/10.1086/378341

Brines, J. (1994). Economic Dependency, Gender, and the Division of Labor at Home. American Journal of Sociology, 100 (3), 652-688. http://dx.doi.org/10.1086/230577

Cameron, A., \& Trivedi, P. (2005). Microeconometrics: Methods and Applications. Cambridge: Cambridge University Press. http://dx.doi.org/10.1017/СB09780511811241

Coltrane, Scott. (2000). Research on Household Labor: Modeling and Measuring the Social Embeddedness of Routine Family Work. Journal of Marriage and the Family 62 (4): 1208 - 1233. http://dx.doi.org/10.1111/j.1741-3737.2000.01208.x

Dougherty, C. (2006). The Marriage Earnings Premium as a Distributed Fixed Effect. Journal of Human Resources 2006, 41, 433-443.

Duncan, Otis D. (1966). Methodological issues in the analysis of social mobility. Pp. 51-97 in Neil J. Smelser and Seymour Martin Lipset (eds.), Social Structure and Mobility in Economic Development. Chicago: Aldine

Dush, C., Cohan, C., \& Amato, P. (2003). The Relationship between Cohabitation and Marital Quality and Stability: Change across Cohorts? Journal of Marriage and Family, 65, 539-549. http://dx.doi.org/10.1111/j.1741-3737.2003.00539.x

Gelman, A., Carlin, J., Stern, H. and Rubin, D. (2005). Bayesian Data Analysis. Third Edition. Chapman and Hall.

Gershuny, J., Bittman, M., Brice, J. (2005). Exit, Voice and Suffering: Do Couples Adapt to Changing Employment Patterns? Journal of Marriage and Family, 67 (3): 656-665. http://dx.doi.org/10.1111/j.1741-3737.2005.00160.x

Ginther, D.K., and Zavodny, M. (2001). Is the Male Marriage Premium Due to Selection? The Effect of Shotgun Weddings on the Return to Marriage. Journal of Population Economics, 14, 313-328. http://dx.doi.org/10.1007/s001480000058

Gupta, S. (1999). The Effects of Transitions in Marital Status on Men's Performance of Housework. Journal of Marriage and the Family, 61, 700-711. http://dx.doi.org/10.2307/353571

Gupta, S. (2006). Her Money her Time: Women's Earnings and their Housework Hours. Social Science Research, 35, 975-999. http://dx.doi.org/10.1016/j.ssresearch.2005.07.003

Gupta, S. (2007). Autonomy, Dependence, or Display? The Relationship between Married Women's Earnings and Housework. Journal of Marriage and Family, 69, 399-417. http://dx.doi.org/10.1111/j.1741-3737.2007.00373.x 
Gupta, S. and Ash, M. (2009). Whose money, whose time? A nonparametric approach to modeling time spent on housework in the United States. Feminist Economics, 14 (1), 93-120. http://dx.doi.org/10.1080/13545700701716664

Gupta, S., Evertsson, M., Grunow, D., Nermo, M., and Sayer, L. (2010). Economic Inequality and Housework. In Treas, J., and Drobnič. (Eds). Dividing the Domestic. Men, Women, and Household Work in CrossNational Perspective (105-122). Stanford: Stanford University Press. http://dx.doi.org/10.11126/stanford/9780804763578.003.0006

Hakim, C. (2000). Work, Life-Style Choices in the Twenty First Century: Preference Theory. Oxford: Oxford University Press.

Han, S-K., \& Moen, P. (1999). Work and Family Over Time: A Life Course Approach. Annals of the American Academy of Political and Social Science. 562, 98-110. http://dx.doi.org/10.1177/0002716299562001007

Haynes, M. Western, M., Yu, L. and Spallek, M. (2008). Analysing Nominal Data from a Panel Survey: Employment Transitions of Australian Women. 103rd Annual Meeting of the American Sociological Association, 1-4 August, 2008, Boston, USA.

Heckman, J. (2005). The Scientific Model of Causality. Sociological Methodology, 35, 1-97. http://dx.doi.org/10.1111/j.0081-1750.2006.00163.x

Kulu, H. and Steele, F. (2013). Interrelationships between childbearing and housing transitions in the family life course. Demography, 50, 1687-1714. http://dx.doi.org/10.1007/s13524-013-0216-2

Lundin, A., Lundberg, I., Hallsten, L., Otosson, J., \& Hemmingsson, T. (2010). Unemployment and Mortality - A Longitudinal Prospective Study on Selection and Causation in 49321 Swedish Middle-Aged Men. Journal of Epidemiology and Community Health, 64, 22-28. http://dx.doi.org/10.1136/jech.2008.079269

McLanahan, S., \& Perchesky, C., (2008). Family Structure and the Reproduction of Inequalities. Annual Review of Sociology, 34, 257-276. http://dx.doi.org/10.1146/annurev.soc.34.040507.134549

Morgan, S.,and Winship, C. (2007). Counterfactuals and Causal Inference: Methods and Principles for Social Research. Cambridge: Cambridge University Press. http://dx.doi.org/10.1017/СВ09780511804564

Oppenheimer, V. (1997). Women's Employment and the Gain to Marriage: The Specialization and Trading Model. Annual Review of Sociology, 23, 431-453. http://dx.doi.org/10.1146/annurev.soc.23.1.431

Pettitt, A., Tran, T., Haynes, M., \& Hay, J. (2006). A Bayesian Hierarchical Model for Categorical Longitudinal Data from a Social Survey of Immigrants. Journal of the Royal Statistical Society - Series A, 169 (1), 97-114. http://dx.doi.org/10.1111/j.1467-985X.2005.00389.x

Shelton, B. \& John, D. (1993). Does Marital Status Make a Difference? Housework among Married and Cohabiting Men and Women. Journal of Family Issues, 14 (3), 401-420. http://dx.doi.org/10.1177/019251393014003004

Sobel, M. (1981). Diagonal Mobility Models: A Substantively Motivated Class of Designs for the Analysis of Mobility Effects. American Journal of Sociology, 46, 893-906. http://dx.doi.org/10.2307/2095086

South, S. J. \& Spitze, G. (1994). Housework in Marital and Nonmarital Households. American Sociological Review, 59 (3), 327-347. http://dx.doi.org/10.2307/2095937 
Spiegelhalter, D., Thomas, A. \& Best, N. (1998). WinBUGS: Bayesian Inference using Gibbs Sampling, Manual version 1.2, Imperial College, London and Medical Research Council Biostatistics Unit, Cambridge.

Steele, F., Kallis, C., Goldstein, H. \& Joshi, H. (2005). The relationship between childbearing and transitions from marriage and cohabitation in Britain. Demography, 42 (4), 647-673. http://dx.doi.org/10.1353/dem.2005.0038

Steele, F., Kallis, C. \& Joshi, H. (2006). The formation and outcomes of cohabiting and marital partnerships in early adulthood: the role of previous partnership experience. Journal of the Royal Statistical SocietySeries A, 169 (4), 757-779. http://dx.doi.org/10.1111/j.1467-985X.2006.00420.x

Steele, F. (2011). Multilevel Discrete-Time Event History Models with Applications to the Analysis of Recurrent Employment Transitions. Australian and New Zealand Journal of Statistics, 53 (1), 1-26. http://dx.doi.org/10.1111/j.1467-842X.2011.00604.x

Sullivan, O. (2011). An End to Gender Display through the Performance of Housework? A Review and Reassessment of the Quantitative Literature using Insights from the Qualitative Literature. Journal of Family Theory and Review, 3, 1-13. http://dx.doi.org/10.1111/j.1756-2589.2010.00074.x

Tolsma, J., de Graaf, N. \& Quillian, L., (2009). Does Intergenerational Social Mobility affect Antagonistic Attitudes towards Ethnic Minorities? British Journal of Sociology, 60, 257-277. http://dx.doi.org/10.1111/j.1468-4446.2009.01230.x

Treas, J., and Drobnič. (Eds) (2010). Dividing the Domestic. Men, Women, and Household Work in Cross-National Perspective. Stanford: Stanford University Press. http://dx.doi.org/10.11126/stanford/9780804763578.001.0001

Upchurch, D., Lillard, L. and Panis, C. (2002). Nonmarital childbearing: Influences of education, marriage and fertility. Demography, 39, 311-329. http://dx.doi.org/10.1353/dem.2002.0020

Watson, N. \& Wooden, M. (2002a). The Household, Income and Labour Dynamics in Australia (HILDA) Survey. HILDA Project Technical Paper Series. No, 1/02, May 2002.

Watson, N. \& Wooden, M. (2002b). The Household, Income and Labour Dynamics in Australia (HILDA) Survey: Wave 1 survey methodology. Melbourne: The University of Melbourne.

Watson, N. and Wooden, M. (2012). The HILDA Survey: a case study in the design and development of a successful household panel study. Longitudinal and Life Course Studies, 3 (3), 369-381.

\section{Endnotes}

${ }^{1}$ This argument is similar to Hakim's (2000) view that some women may have home-centred preferences. 
Table 1: Means, standard deviations, proportions of housework hours and model covariates for pooled sample of women aged 18-45 years, HILDA waves $2-8^{a}$.

\begin{tabular}{|c|c|c|}
\hline \multirow[b]{2}{*}{ Model Variables } & \multicolumn{2}{|c|}{ HILDA $(2-8)$} \\
\hline & Mean $^{\mathrm{b}}$ & $S^{c}$ \\
\hline Housework hours & 17.81 & 13.3 \\
\hline Housework hours (logged) & 2.60 & 0.8 \\
\hline Age & 36.93 & 7.9 \\
\hline Earnings $(\$ 10,000)$ & 2.80 & 2.10 \\
\hline Bachelor Degree or higher (1=yes) & $30 \%$ & \\
\hline \multicolumn{3}{|l|}{ Number of children $<18$} \\
\hline None & $38 \%$ & \\
\hline 1 child & $12 \%$ & \\
\hline 2 children & $27 \%$ & \\
\hline $3+$ children & $23 \%$ & \\
\hline \multicolumn{3}{|l|}{ Employment status: } \\
\hline Not employed & $25 \%$ & \\
\hline Employed Full time & $39 \%$ & \\
\hline Employed Part time & $36 \%$ & \\
\hline \multicolumn{3}{|l|}{ Relationship Status Duration (Months) } \\
\hline Married & 159 & 97 \\
\hline Cohabiting & 34 & 24 \\
\hline Single & 46 & 26 \\
\hline
\end{tabular}

Transition variables

Birth

Remain married

$55.6 \%$

Remain cohabiting

$11.1 \%$

Remain single

$26.0 \%$

Single-Married

$0.7 \%$

Single-Cohabiting

$2.6 \%$

Married-Separated

$1.2 \%$

Cohabiting-Separated

$1.3 \%$

Cohabiting-Married

$1.5 \%$

Woman-years

Number of women

${ }^{a}$ Analytic sample includes data from wave 2 as not all partnership transitions are available at wave 1

${ }^{\mathrm{b}}$ Means reported for continuous measures and percentages (\%) reported for categorical measures

${ }^{\mathrm{c}}$ Standard deviations reported only for continuous measures. 
Table 2: Estimated coefficients and standard errors from models of change in log housework hours for single, cohabiting and married women aged $18-45$ years. $^{\text {a }}$

\begin{tabular}{|c|c|c|c|c|c|c|}
\hline \multirow[t]{2}{*}{ Variable } & \multicolumn{2}{|c|}{$\begin{array}{c}\text { Single State Model for Log } \\
\text { Housework Hours }\end{array}$} & \multicolumn{2}{|c|}{$\begin{array}{c}\text { Cohabit State Model for Log } \\
\text { Housework Hours }\end{array}$} & \multicolumn{2}{|c|}{$\begin{array}{c}\text { Married State Model for Log } \\
\text { Housework Hours }\end{array}$} \\
\hline & Coeff & SE & Coeff & SE & Coeff & SE \\
\hline Constant & $2.198 *$ & 0.040 & $2.498^{*}$ & 0.065 & $2.749 *$ & 0.031 \\
\hline Age & $0.014^{*}$ & 0.002 & $0.008^{*}$ & 0.003 & $0.005^{*}$ & 0.002 \\
\hline Age squared & $-0.001 *$ & 0.0002 & -0.0005 & 0.0003 & -0.0003 & 0.0002 \\
\hline Earnings (log ‘0,000s) & $0.105^{*}$ & 0.030 & -0.024 & 0.037 & $-0.107^{*}$ & 0.017 \\
\hline Male breadwinner attitudes & $0.012^{*}$ & 0.002 & 0.001 & 0.005 & $0.007^{*}$ & 0.002 \\
\hline Bachelor degree (1=yes) & 0.055 & 0.032 & -0.005 & 0.044 & 0.016 & 0.025 \\
\hline \multicolumn{7}{|l|}{ Birth of child } \\
\hline \multicolumn{7}{|l|}{ No birth } \\
\hline Birth & 0.105 & 0.058 & 0.023 & 0.050 & $0.094^{*}$ & 0.024 \\
\hline \multicolumn{7}{|l|}{ Number of children $<18$} \\
\hline \multicolumn{7}{|l|}{ None } \\
\hline 1 child & $0.492^{*}$ & 0.044 & $0.335^{*}$ & 0.050 & $0.173^{*}$ & 0.028 \\
\hline 2 children & $0.465^{*}$ & 0.043 & $0.516^{*}$ & 0.050 & $0.300 *$ & 0.025 \\
\hline $3+$ children & $0.535^{*}$ & 0.046 & $0.529 *$ & 0.061 & $0.363 *$ & 0.027 \\
\hline \multicolumn{7}{|l|}{ Employment } \\
\hline \multicolumn{7}{|l|}{ Not employed } \\
\hline Employed Full-time & $-0.304 *$ & 0.031 & $-0.373^{*}$ & 0.044 & $-0.406 *$ & 0.022 \\
\hline Employed Part-time & $-0.193^{*}$ & 0.028 & $-0.195^{*}$ & 0.039 & $-0.177^{*}$ & 0.018 \\
\hline Duration in current marital status & -0.0002 & 0.0003 & -0.0004 & 0.0005 & 0.00009 & 0.0002 \\
\hline Trans S-C & $0.169 *$ & 0.033 & & & & \\
\hline Trans S-M & $0.333^{*}$ & 0.064 & & & & \\
\hline Trans C-S & & & $-0.104^{*}$ & 0.047 & & \\
\hline Trans C-M & & & 0.033 & 0.045 & & \\
\hline Trans M-S & & & & & -0.068 & 0.044 \\
\hline
\end{tabular}

a. Estimated values are means of posterior distributions obtained from 46,000 MCMC simulations, following a burn-in of 4,000.

b. * indicates that the $95 \%$ credible interval for the estimated regression coefficient does not contain zero. 
Table 3: Estimated coefficients and standard errors from models of log odds of partnership formation for women aged 18-45 years. ${ }^{a}$

\begin{tabular}{|c|c|c|c|c|c|c|}
\hline \multirow[t]{2}{*}{ Variable } & \multicolumn{2}{|c|}{$\begin{array}{l}\text { Model for Transition } \\
\text { Single-Married }\end{array}$} & \multicolumn{2}{|c|}{$\begin{array}{l}\text { Model for Transition Single- } \\
\text { Cohabiting }\end{array}$} & \multicolumn{2}{|c|}{$\begin{array}{c}\text { Model for Transition } \\
\text { Cohabiting-Married }\end{array}$} \\
\hline & Coeff & SE & Coeff & SE & Coeff & $\mathrm{SE}$ \\
\hline Constant & $-5.215^{*}$ & 0.831 & $-2.390 *$ & 0.169 & $-1.711^{*}$ & 0.353 \\
\hline Age & $-0.064 *$ & 0.022 & $-0.068 *$ & 0.009 & $-0.057^{*}$ & 0.015 \\
\hline Age_squared & $-0.006^{*}$ & 0.002 & $-0.004 *$ & 0.0009 & $-0.006^{*}$ & 0.002 \\
\hline $\begin{array}{l}\text { Lag earnings } \\
\text { (log } ` 0,000 s)\end{array}$ & 0.018 & 0.062 & $0.064^{*}$ & 0.022 & 0.081 & 0.071 \\
\hline Bachelor degree (1=yes) & $0.703^{*}$ & 0.365 & 0.114 & 0.133 & $0.475^{*}$ & 0.221 \\
\hline $\begin{array}{l}\text { Birth of child } \\
\text { No birth }\end{array}$ & & & & & & \\
\hline First birth & 0.237 & 0.767 & $1.793^{*}$ & 0.273 & 0.036 & 0.316 \\
\hline $\begin{array}{l}\text { Number of children }<18 \\
\text { None }\end{array}$ & & & & & & \\
\hline 1 child & -0.039 & 0.476 & -0.232 & 0.199 & -0.014 & 0.270 \\
\hline 2 children & 0.281 & 0.441 & $-0.533^{*}$ & 0.206 & $-0.827^{*}$ & 0.302 \\
\hline $3+$ children & 0.346 & 0.473 & $-0.663^{*}$ & 0.238 & -0.349 & 0.315 \\
\hline $\begin{array}{l}\text { Duration in previous marital } \\
\text { status }\end{array}$ & $0.008^{*}$ & 0.005 & 0.002 & 0.002 & 0.006 & 0.005 \\
\hline Lag housework hours (log) & 0.006 & 0.018 & 0.004 & 0.023 & 0.006 & 0.018 \\
\hline
\end{tabular}

a. Estimated values are means of posterior distributions obtained from 46,000 MCMC simulations, following a burn-in of 4,000.

b. ${ }^{*}$ indicates that the $95 \%$ credible interval for the estimated regression coefficient does not contain zero. 
Table 4: Estimated coefficients and standard errors from models of log odds of partnership dissolution for women aged 18-45 years. $^{\text {a }}$

\begin{tabular}{|c|c|c|c|c|}
\hline \multirow[b]{2}{*}{ Variable } & \multicolumn{2}{|c|}{ Model for Transition Cohabiting-Single } & \multicolumn{2}{|c|}{ Model for Transition Married-Single } \\
\hline & Coeff & SE & Coeff & SE \\
\hline Constant & $-3.990 *$ & 0.407 & $-3.943^{*}$ & 0.258 \\
\hline Age & -0.010 & 0.014 & -0.009 & 0.016 \\
\hline Age_squared & $-0.002 *$ & 0.002 & -0.001 & 0.002 \\
\hline Lag earnings & $-0.206^{*}$ & 0.061 & -0.047 & 0.076 \\
\hline \multicolumn{5}{|l|}{ (log '0,000s) } \\
\hline Bachelor degree (1=yes) & -0.410 & 0.226 & $-0.581 *$ & 0.197 \\
\hline \multicolumn{5}{|l|}{ Birth of child } \\
\hline \multicolumn{5}{|l|}{ No birth } \\
\hline Birth & $-0.993^{*}$ & 0.433 & $-1.157^{*}$ & 0.460 \\
\hline \multicolumn{5}{|l|}{ Number of children $<18$} \\
\hline \multicolumn{5}{|l|}{ None } \\
\hline 1 child & 0.503 & 0.255 & -0.446 & 0.282 \\
\hline 2 children & -0.342 & 0.279 & -0.206 & 0.220 \\
\hline $3+$ children & -0.221 & 0.295 & -0.347 & 0.239 \\
\hline Duration in previous marital status & $-0.016^{*}$ & 0.005 & $-0.002 *$ & 0.001 \\
\hline Lag housework hours (log) & 0.004 & 0.023 & -0.006 & 0.030 \\
\hline
\end{tabular}

a. Estimated values are means of posterior distributions obtained from 46,000 MCMC simulations, following a burn-in of 4,000.

b. * indicates that the $95 \%$ credible interval for the estimated regression coefficient does not contain zero. 
Table 5: Estimated random-effects covariance matrix from the multi-process model (includes estimates of correlation in [ ]).

\begin{tabular}{|c|c|c|c|c|c|c|c|c|}
\hline & $\begin{array}{c}\text { Housework } \\
\text { hours for } \\
\text { single state }\end{array}$ & $\begin{array}{c}\text { Housework } \\
\text { hours for } \\
\text { married }\end{array}$ & $\begin{array}{c}\text { Housework } \\
\text { hours for } \\
\text { cohabiting }\end{array}$ & $\begin{array}{l}\text { Likelihood of } \\
\text { S-M transition }\end{array}$ & $\begin{array}{l}\text { Likelihood of } \\
\text { S-C transition }\end{array}$ & $\begin{array}{l}\text { Likelihood of } \\
\text { C-M transition }\end{array}$ & $\begin{array}{l}\text { Likelihood of } \\
\text { C-S transition }\end{array}$ & $\begin{array}{l}\text { Likelihood of } \\
\text { M-S transition }\end{array}$ \\
\hline $\begin{array}{l}\text { Housework } \\
\text { hours for single } \\
\text { state }\end{array}$ & $0.263^{*}$ & & & & & & & \\
\hline $\begin{array}{l}\text { Housework } \\
\text { hours for } \\
\text { married }\end{array}$ & $\begin{array}{l}0.135^{*} \\
{[0.605]}\end{array}$ & $0.189 *$ & & & & & & \\
\hline $\begin{array}{l}\text { Housework } \\
\text { hours for } \\
\text { cohabiting }\end{array}$ & $\begin{array}{l}0.172 * \\
{[0.696]}\end{array}$ & $\begin{array}{l}0.126 * \\
{[0.601]}\end{array}$ & $0.232 *$ & & & & & \\
\hline $\begin{array}{l}\text { Likelihood of S-M } \\
\text { transition }\end{array}$ & $\begin{array}{c}0.027 \\
{[0.021]}\end{array}$ & $\begin{array}{c}-0.096 \\
{[-0.089]}\end{array}$ & $\begin{array}{c}0.096 \\
{[0.081]}\end{array}$ & $6.119 *$ & & & & \\
\hline $\begin{array}{l}\text { Likelihood of S-C } \\
\text { transition }\end{array}$ & $\begin{array}{c}0.069 \\
{[0.133]}\end{array}$ & $\begin{array}{c}-0.008 \\
{[-0.018]}\end{array}$ & $\begin{array}{c}0.023 \\
{[0.047]}\end{array}$ & $\begin{array}{c}0.654 \\
{[0.262]}\end{array}$ & $1.019 *$ & & & \\
\hline $\begin{array}{l}\text { Likelihood of C- } \\
\text { M transition }\end{array}$ & $\begin{array}{c}0.018 \\
{[0.025]}\end{array}$ & $\begin{array}{c}-0.031 \\
{[-0.051]}\end{array}$ & $\begin{array}{c}0.046 \\
{[0.068]}\end{array}$ & $\begin{array}{c}2.110 \\
{[0.610]}\end{array}$ & $\begin{array}{l}0.339 * \\
{[0.240]}\end{array}$ & 1.954 & & \\
\hline $\begin{array}{l}\text { Likelihood of C-S } \\
\text { transition }\end{array}$ & $\begin{array}{c}0.027 \\
{[0.047]}\end{array}$ & $\begin{array}{c}0.018 \\
{[0.037]}\end{array}$ & $\begin{array}{l}-0.031 \\
{[0.057]}\end{array}$ & $\begin{array}{c}-0.085 \\
{[-0.031]}\end{array}$ & $\begin{array}{l}0.479 * \\
{[0.424]}\end{array}$ & $\begin{array}{l}-0.266 \\
{[0.170]}\end{array}$ & 1.253 & \\
\hline $\begin{array}{l}\text { Likelihood of M-S } \\
\text { transition }\end{array}$ & $\begin{array}{c}0.077 \\
{[0.122]}\end{array}$ & $\begin{array}{l}-0.011 \\
{[0.020]}\end{array}$ & $\begin{array}{c}0.044 \\
{[0.074]}\end{array}$ & $\begin{array}{l}0.952 * \\
{[0.312]}\end{array}$ & $\begin{array}{l}0.762 * \\
{[0.612]}\end{array}$ & $\begin{array}{c}0.325 \\
{[0.188]}\end{array}$ & $\begin{array}{c}0.426 \\
{[0.309]}\end{array}$ & $1.522^{*}$ \\
\hline
\end{tabular}

